\title{
Cyclopenta[b]indole Derivative Inhibits Aurora B in Primary Cells
}

\author{
Andreas Ekebergh, Jerker Mårtensson, and Christine Lingblom Ekebergh*
}

Cite This: ACS Omega 2020, 5, 33455-33460

Read Online

ABSTRACT: The Aurora family of kinases is closely involved in regulating cell division. Inhibition of Aurora A and B with small molecules is currently being investigated in clinical trials for the treatment of different cancers. It has also been evaluated as a treatment option against different autoimmune diseases in preclinical studies. Here, we present a cyclopenta $[b]$ indole derivative capable of inhibiting Aurora B selectively in kinase assays. To evaluate the Aurora B inhibition capacity of the compound, we used a kinase $\mathrm{IC}_{50}$ assay as well as a suppression

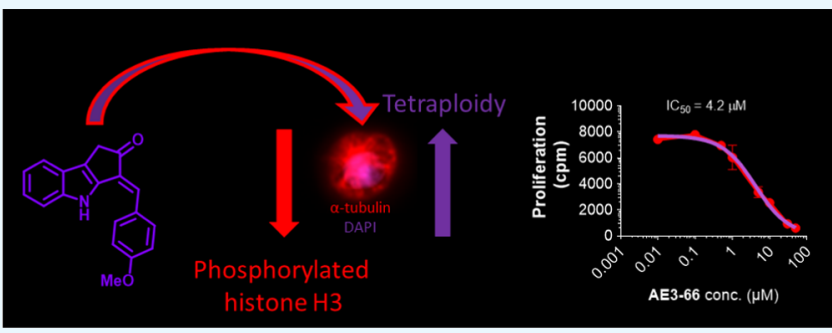
assay of proliferating primary cells. In addition, we examined if the cells had gained a phenotype characteristic for Aurora B inhibition after treatment with the compound. We found that the compound selectively inhibited Aurora B $\left(\mathrm{IC}_{50}=1.4 \mu \mathrm{M}\right)$ over Aurora A $\left(\mathrm{IC}_{50}>30 \mu \mathrm{M}\right)$. Moreover, the compound inhibited proliferating PBMCs with an $\mathrm{IC}_{50}=4.2 \mu \mathrm{M}$, and the cells displayed reduced phosphorylation of histone $\mathrm{H} 3$ as well as tetraploidy, consistent with Aurora B inhibition.

\section{INTRODUCTION}

The Aurora family of kinases, consisting of Aurora A, B, and C, is closely involved in cell division. These kinases participate in all stages of mitosis and serve several different functions. While structurally similar, the functions and their cellular localization differ between the kinases. In short, during mitosis, Aurora A is primarily present in the centrosomes, where it has a critical function to ensure proper mitotic spindle assembly. ${ }^{1,2}$ For instance, inhibition or knockout of Aurora A produces cells with monopolar spindles. ${ }^{3,4}$ Aurora B is mainly localized at the centromeres of the chromosomes, where one of its functions is to assist with correct attachment of microtubules to the kinetochores. ${ }^{5,6}$ Previous reports have revealed that Aurora B inhibition leads to, among other cell effects, suppression of cell proliferation and causes cell death. ${ }^{7-9}$ When Aurora B is knocked out or inhibited in cells, it leads to reduced amounts of phosphorylated histone $\mathrm{H} 3$ and polyploidy. ${ }^{7,8,10-12}$ Aurora $\mathrm{C}$ is less studied than the other Aurora kinases. It is mostly found in testis tissue and studies indicate that it is functionally similar to Aurora B. ${ }^{13-15}$

Aurora A is heavily implicated in tumorigenesis. Amplification and overexpression of the protein have been observed in a wide variety of tumors. ${ }^{16-18}$ Whether Aurora B affects tumorigenesis or not is at present unclear; higher levels of the protein have, however, been found in several different cancers. ${ }^{2,17,19,20}$ The association between cell division and Aurora kinase function and their dysregulation in cancers have propelled the development of Aurora inhibitors. ${ }^{21,22}$ Several inhibitors have displayed promising results in preclinical cancer models, with, for instance, low nanomolar antiproliferative potency against cancer cell lines and high efficiency in in vivo models. More than 10 Aurora inhibitors, either isoformselective or pan-Aurora inhibitors, have entered clinical trials for different cancers, but none has so far been approved. Recently, the role of Aurora A and B has also been highlighted in a number of autoimmune diseases, e.g., rheumatoid arthritis $^{23}$ and autoimmune encephalomyelitis. ${ }^{24}$ Further studies to find new small molecular lead structures that can be optimized into selective and less toxic Aurora inhibitors are thus warranted.

We have previously reported that a series of compounds based on a cyclopenta[b]indole-2-one core appended with arylidene substituents in the 3-position inhibit Aurora A and Aurora B kinases in protein assays. ${ }^{25}$ Herein, we characterize the Aurora-inhibiting properties of the most potent derivative AE3-66 (Figure 1) from our previous screening and evaluate its ability to induce a cellular phenotype associated with Aurora inhibition in peripheral blood mononuclear cells (PBMCs).

\section{RESULTS AND DISCUSSION}

AE3-66 Inhibits Aurora B Selectively over Aurora A. We have previously only measured the ability of AE3-66 to inhibit Aurora A and B at a single concentration. Aurora A and $\mathrm{B}$ inhibition was studied here over a range of compound concentrations in a radiometric assay. The $\mathrm{IC}_{50}$ was above 30

Received: November 10, 2020

Accepted: November 27, 2020

Published: December 16, 2020 


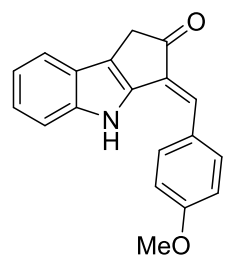

Figure 1. Chemical structure of Aurora inhibitor AE3-66.

$\mu \mathrm{M}$ (data not shown) and $1.6 \mu \mathrm{M}$ (Figure 2) for Aurora $\mathrm{A}$ and Aurora B, respectively. Consequently, AE3-66 displays more

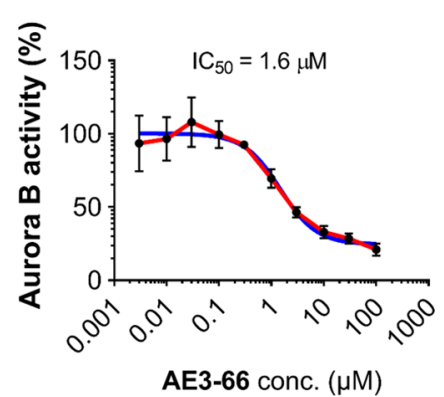

Figure 2. Inhibition of Aurora B kinase by AE3-66 at 10 different concentrations. The red line connects data points and the blue line shows the curve fit.

than 20-fold selectivity for Aurora B over A. To further assess the selectivity of AE3-66, a kinase panel designed to cover all areas of the human kinome was screened at $10 \mu \mathrm{M}$ inhibitor concentration. Of the 50 screened kinases, AE3-66 displayed the highest inhibitory effect toward Aurora B, albeit also targeting HIPK2 and PIM1 (Figure 3). The binding mode of AE3-66 was studied using in silico docking to crystal structures of human and frog (X. laevis) Aurora B. The lowest energy binding modes place AE3-66 in the ATP cleft in similar conformations in both cases (Figures S1 and S2). The selectivity toward Aurora B prompted us to continue investigating whether AE3-66 could induce a cellular phenotype associated with Aurora B inhibition.
AE3-66 Suppresses Proliferating PBMCs. Due to previous reports that demonstrated that Aurora B inhibition leads to suppression of cell proliferation and causes cell death, ${ }^{7-9}$ we wanted to study if this behavior is mirrored with our compound. To investigate the effect of AE3-66 on proliferating cells, polyclonally activated PBMCs were cocultured with the inhibitor at seven different concentrations. We chose to work with freshly isolated PBMCs because they mimic the natural environment well with both pro-inflammatory and anti-inflammatory mechanisms that can contribute to the results. ${ }^{26-28}$ After $48 \mathrm{~h}$, the cellular proliferation was determined by measuring incorporation of ${ }^{3} \mathrm{H}$-thymidine. Furthermore, the viability was measured with flow cytometry using a fixable live/dead stain. The inhibitor suppressed proliferation with an $\mathrm{IC}_{50}$ of $4.2 \mu \mathrm{M}$ (Figure 4).

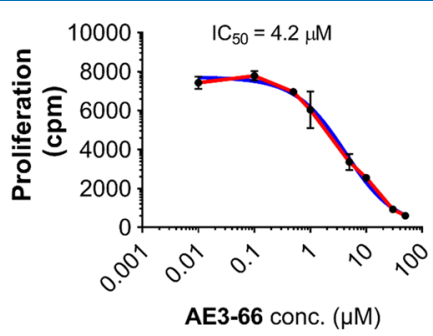

Figure 4. Kinase inhibitor AE3-66 suppresses the proliferation of PBMCs; 100.000 PBMCs stimulated by CD3/CD28 cross-linking ( $n$ $=2$ ) are suppressed by kinase inhibitor AE3-66. Cellular proliferation was measured via the incorporation of ${ }^{3} \mathrm{H}$-thymidine. Cell proliferation was quantified as counts per minutes (cpm). The red line connects data points and the blue line shows the curve fit.

The cellular viability was not greatly affected over this concentration range and even at $50 \mu \mathrm{M}$, only $50 \%$ of the cells were found to be nonviable (Figure 5).

The Aurora B inhibitor GSK1070916 displayed $\mathrm{IC}_{50} \mathrm{~s}$ in several cancer cell lines in the same range as it inhibited Aurora B in kinase assays. ${ }^{7,29}$ Similarly, the Aurora B inhibitor AZD1152 displayed 3-10 times higher cellular $\mathrm{IC}_{50} \mathrm{~s}$ compared to $\mathrm{IC}_{50} \mathrm{~s}$ measured in kinase inhibition assays

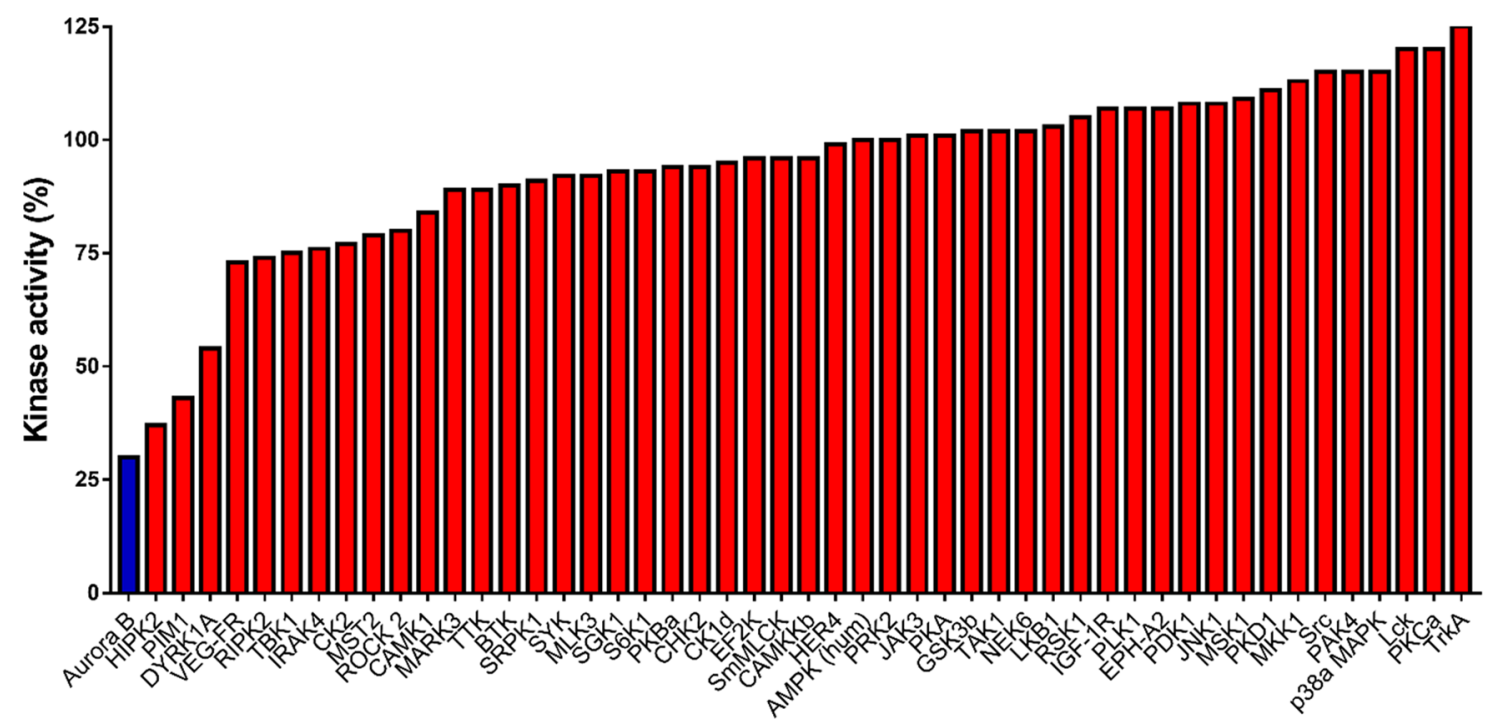

Figure 3. Kinase selectivity profile of AE3-66 against a selection of 50 kinases representing the human kinome. AE3-66 was assayed at $10 \mu \mathrm{M}$ concentration. 


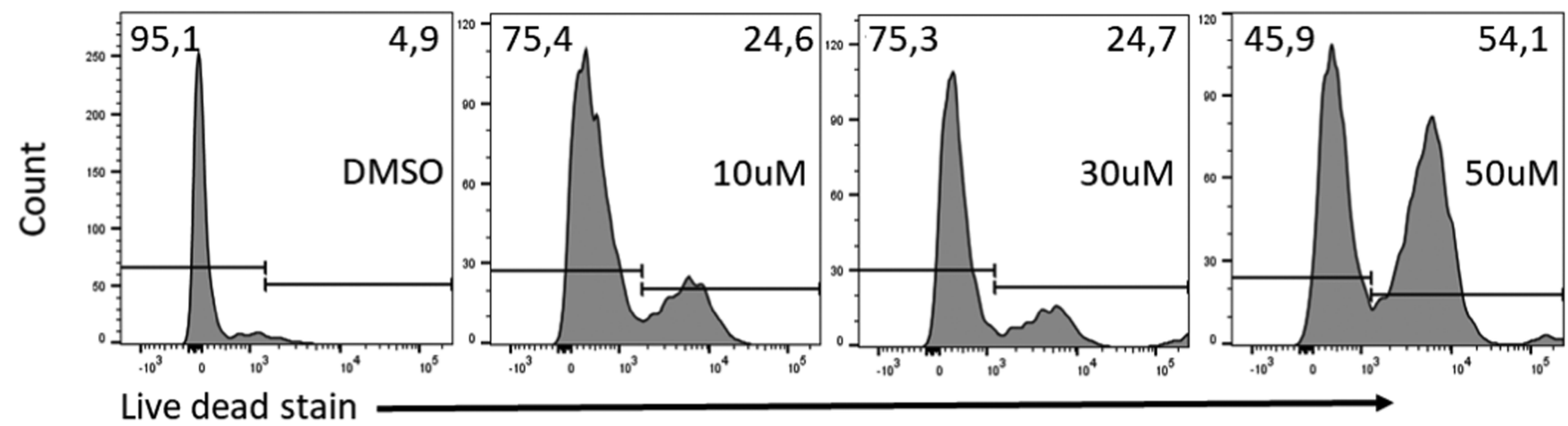

Figure 5. Percentage of dead cells after treatment with kinase inhibitors at the different concentrations. Staining with fixable viability dye after treatment with AE3-66. Representative histograms of PBMCs expressing the viability dye. From left to right: $\mathrm{PBMC}+\mathrm{DMSO}, \mathrm{PBMC}+10 \mu \mathrm{M}$ $\mathrm{AE} 3-66, \mathrm{PBMC}+30 \mu \mathrm{M} \mathrm{AE3}-66$, and $\mathrm{PBMC}+50 \mu \mathrm{M}$ AE3-66.

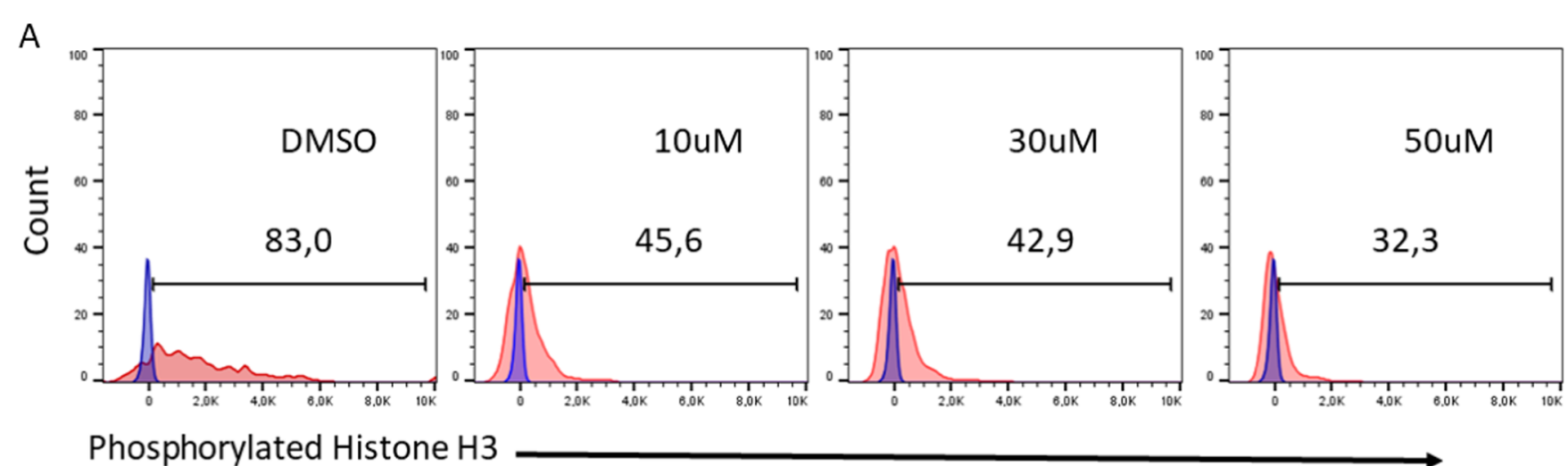

B
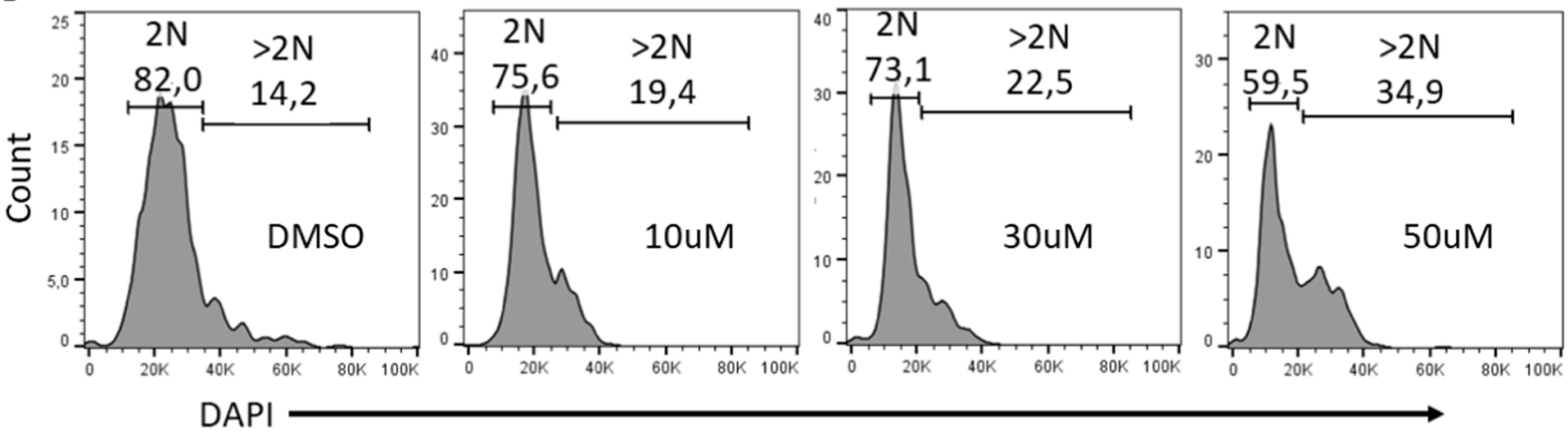

Figure 6. (A) Representative histograms of PBMCs expressing phosphorylated histone H3. From left to right: $\mathrm{PBMC}+\mathrm{DMSO}, \mathrm{PBMC}+10 \mu \mathrm{M}$ $\mathrm{AE3}-66, \mathrm{PBMC}+30 \mu \mathrm{M}$ AE3-66, and PBMC $+50 \mu \mathrm{M}$ AE3-66. (B) Representative histograms of PBMCs expressing the DNA stain DAPI. From left to right: PBMC + DMSO, PBMC $+10 \mu \mathrm{M}$ AE3-66, PBMC + $30 \mu \mathrm{M}$ AE3-66, and PBMC + 50 $\mu \mathrm{M}$ AE3-66. Bars indicate the percentage of cells expressing $2 \mathrm{~N}$ DNA and $>2 \mathrm{~N}$ DNA.

when treating leukemia cells isolated from peripheral blood or blood marrow. ${ }^{8}$ The cellular $\mathrm{IC}_{50}$ for stimulated PBMCs treated with AE3-66 reported here, which was $\sim$ three times higher than the inhibition displayed in the kinase assay, is thus in line with what has been reported previously.

AE3-66 Reduces Phosphorylated Histone H3 and Induces Tetraploidy. Next, we investigated the phenotype induced by AE3-66 more thoroughly. The cellular phenotype resulting from impaired Aurora B function has previously been studied using mutant Aurora B-transfected cells, smallmolecule inhibition, and RNAi. ${ }^{12}$ Exchanging the lysine residue (Lys106) necessary for ATP binding to arginine diminished the ability of Aurora B to phosphorylate histone $\mathrm{H} 3$ at Ser10 in transfected cells. ${ }^{10,11}$ The transfected cells also displayed polyploidy, indicating cell cycle progression without cell division, which is a hallmark for antitumor and antiinflammatory activities. Identical phenotypic behavior has been observed when treating cells with small-molecule Aurora B inhibitors, i.e., reduced amounts of phosphorylated histone $\mathrm{H} 3$ and polyploidy. ${ }^{7,8}$

To investigate whether AE3-66 could induce the characteristic phenotype associated with Aurora B inhibition explained above, flow cytometry was used to measure the extent of phosphorylation of histone $\mathrm{H} 3$ (Ser10) and cellular DNA content. The expression of phosphorylated histone $\mathrm{H} 3$ was measured relative to "Fluorescence Minus One"-controls, which monitor background staining. Any fluorescence from the inhibitor can as such perturb the output. To exclude such 
assay interference and ascertain a specific fluorescence signal, we performed spectrometric measurements of AE3-66. AE366 displayed absorbance up to $520 \mathrm{~nm}$ and a weak fluorescence up to $750 \mathrm{~nm}$ (data not shown). Consequently, an Alexa Fluor 647-conjugated antibody, which can be excited using the 633 nm laser, was chosen to study phosphorylation of histone $\mathrm{H} 3$. The DNA content was measured using the DNA dye DAPI. Fluorescence output from DAPI produces populations of cells having $2 \mathrm{~N}, 4 \mathrm{~N}$, and $8 \mathrm{~N}$ DNA.

PBMCs treated with the inhibitor for $48 \mathrm{~h}$ displayed a decrease in the phosphorylation of the Aurora $\mathrm{B}$ target histone $\mathrm{H} 3$ (Figure 6A) in a dose-dependent manner. Also, the number of cells showing polyploidy increased in a dosedependent manner when treated with the inhibitor (Figure $6 \mathrm{~B})$. The most profound effect was obtained at the highest inhibitor concentration $(50 \mu \mathrm{M})$, where $35 \%$ of the cells displayed polyploidy. The observed phenotypic behavior agrees with previous studies utilizing other Aurora B inhibitors or Aurora B knockouts, clearly supporting the hypothesis that AE3-66 actively inhibits Aurora B in cells.

Interestingly, the structurally related natural product Nostodione A has, in a previous study, displayed antimitotic properties against sea urchin eggs. ${ }^{30}$ The compound prevented mitosis and proper mitotic spindle alignment and induced polyploidy, all phenotypic behaviors of Aurora B inhibition. The Aurora proteins are highly conserved throughout eukaryotes, albeit nonvertebrates such as sea urchins and starfishes only have one Aurora kinase. ${ }^{31,32}$ However, the starfish Aurora kinase can replace the function of Aurora B in HeLa cells, indicating the close relationship between the two proteins. ${ }^{31}$ We have, in a previous study, shown that Nostodione A does inhibit Aurora kinases, albeit weaker than AE3-66 investigated here. ${ }^{25}$ Similar to what we observe with AE3-66, it is likely that the observed phenotype of Nostodione A-treated sea urchins is due to Aurora inhibition.

\section{CONCLUSIONS}

Taken together, we conclude that AE3-66 can inhibit Aurora $\mathrm{B}$ not only in protein assays but also in a cellular context. PBMCs treated with AE3-66 display a characteristic phenotype of Aurora B inhibition and the antiproliferative effect is also in the expected range when compared to the in vitro inhibition of Aurora B. Furthermore, the compound does not display excessive toxicity. These observations indicate that there are no severe off-target effects that compromise the cells. From this initial study, we cannot, however, definitely rule out that the compound interferes with other cellular functions besides Aurora B inhibition. To transform this molecular structure into a more potent compound, further lead structure optimization is needed.

\section{EXPERIMENTAL SECTION}

Preparation of the Aurora B Inhibitor. AE3-66 was synthesized as described previously. ${ }^{25}$

Kinase Inhibition. Kinase $\mathrm{IC}_{50}$ inhibition assays and kinase screening were performed by the MRC PPU International Centre for Kinase Profiling (http://www.kinase-screen.mrc.ac. $\mathrm{uk} /$ ). A radioactive filter binding assay was used to evaluate the inhibition of Aurora A and Aurora B at 10 different concentrations in duplicate. ${ }^{33,34}$ For curve fitting, nonlinear regression was used to calculate $\mathrm{IC}_{50}$ with a variable slope using GraphPad Prism 7.0 software (GraphPad, San Diego, CA).

In Silico Docking. Crystal structures of human (PDB ID: 4AF3) and X. laevis (PDB ID: 4C2V) Aurora B were used for docking studies. ${ }^{35,36}$ INCENP and ligands were removed in Chimera v.1.14. ${ }^{37}$ Further editing was performed in AutoDock Tools v.1.5.6, which included removing water and adding polar hydrogens. ${ }^{38}$ The AE3-66 structure was optimized in Avogadro v.1.2.0 using the MMFF94 force field and a steepest descent optimization algorithm with a convergence criterion of $10 \times 10^{-7} .39$ AutoDock Vina v.1.1.2 was used to dock AE3-66 to the edited crystal structures. ${ }^{40}$ The input for human Aurora $\mathrm{B}$ was comprised of center_ $\mathrm{x}=10$, center_ $\mathrm{y}=-25$, center $\mathrm{z}=$ -2 , size $\mathrm{x}=30$, size $\mathrm{y}=30$, size $z=30$, and exhaustiveness $=$ 30. The input for $X$. laevis Aurora $\mathrm{B}$ was comprised of center_x $=35$, center_ $y=25$, center $\_z=60$, size $\_x=30$, size $\_y=30$, size $z=26$, and exhaustiveness $=20$.

Suppression Assay of CD3/CD28-Stimulated PBMCs. Peripheral blood mononuclear cells (PBMCs) were isolated from EDTA-anticoagulated blood withdrawn from two healthy subjects. PBMCs $\left(10^{5}\right.$ cells $)$ were added to anti-CD3 mAbcoated (clone OKT3, $1 \mu \mathrm{g} / \mathrm{mL}$, eBioscience, San Diego, CA) 96-well microplate plates (TPP, Trasadingen, Switzerland), followed by anti-CD28 mAb (clone CD28.2, $2 \mu \mathrm{g} / \mathrm{mL}$, eBioscience, San Diego, CA). The activated PBMCs were treated with seven different concentrations $(100 \mathrm{nM}, 500 \mathrm{nM}$, $1 \mu \mathrm{M}, 5 \mu \mathrm{M}, 10 \mu \mathrm{M}, 30 \mu \mathrm{M}$, and $50 \mu \mathrm{M})$ of the Aurora $\mathrm{B}$ inhibitor or vehicle (DMSO $0.05 \%)$. The cell cultures were incubated for $48 \mathrm{~h}$ at $37^{\circ} \mathrm{C}$. To evaluate cellular proliferation, $3 H$-thymidine $(1 \mu \mathrm{Ci} /$ well $)$ was added on the second day of culture. After $6 \mathrm{~h}$, the cells were harvested onto glass fiber filters. Incorporated $3 \mathrm{H}$-thymidine was measured using a $\beta$ counter and quantified as counts per minute $(\mathrm{cpm})$. For curve fitting, nonlinear regression was used to calculate $\mathrm{IC}_{50}$ with a variable slope using GraphPad Prism 7.0 software (GraphPad, San Diego, CA).

Staining of PBMCs for Flow Cytometry Analysis. Cells from $48 \mathrm{~h}$ cultures were fixed and permeabilized using the BD cytofix and cytoperm kit (Becton Dickinson, San Jose, CA) and incubated with Fixable Viability Dye eFluor 780 (eBioscience), DAPI (140 nM, BD Bioscience), and phosphorylated histone $\mathrm{H} 3$ conjugated to Alexa Fluor 647 (clone 11D8, Biolegend, San Diego, CA) for flow cytometry analysis. One thousand events were collected in a FACSCanto II Flow Cytometer (BD Biosciences) and analyzed with Flow Jo (Tree Star Inc., Ashland, OR).

Safety Comment. No unexpected or unusually high safety hazards were encountered.

\section{ASSOCIATED CONTENT}

\section{Supporting Information}

The Supporting Information is available free of charge at https://pubs.acs.org/doi/10.1021/acsomega.0c05491.

Figures of predicted interaction between AE3-66 and Aurora $\mathrm{B}$ based on in silico docking (PDF)

\section{AUTHOR INFORMATION}

\section{Corresponding Author}

Christine Lingblom Ekebergh - Department of Infectious Diseases, Institute of Biomedicine, Sahlgrenska Academy, University of Gothenburg, Gothenburg 413 46, Sweden; Department of Clinical Microbiology, Region Västra 
Götaland, Sahlgrenska University Hospital, Gothenburg 413 46, Sweden; 10 orcid.org/0000-0003-1284-6911; Phone: +46 3134246 23; Email: christinelingblom@ microbio.gu.se; Fax: + 4631411305

\section{Authors}

Andreas Ekebergh - Department of Chemistry and Chemical Engineering, Chalmers University of Technology, Gothenburg 412 96, Sweden; (1) orcid.org/0000-0003-3047-4699

Jerker Mårtensson - Department of Chemistry and Chemical Engineering, Chalmers University of Technology, Gothenburg 412 96, Sweden

Complete contact information is available at:

https://pubs.acs.org/10.1021/acsomega.0c05491

\section{Author Contributions}

J.M. contributed to the molecule design as well as writing of the manuscript. A.E. and C.E. participated in the performance and design of the experiments, the analysis as well as the writing of the manuscript, and supervised the entire study.

\section{Notes}

The authors declare no competing financial interest.

\section{ACKNOWLEDGMENTS}

Financial support from Magnus Bergvalls Stiftelse is gratefully acknowledged. In addition, we want to thank Johan Dahlberg for contribution of blood samples and Sofie Albinsson for technical assistance.

\section{REFERENCES}

(1) Vader, G.; Lens, S. M. The Aurora kinase family in cell division and cancer. Biochim. Biophys. Acta, Rev. Cancer 2008, 1786, 60-72.

(2) Willems, E.; Dedobbeleer, M.; Digregorio, M.; Lombard, A.; Lumapat, P. N.; Rogister, B. The functional diversity of Aurora kinases: a comprehensive review. Cell Div. 2018, 13, 7.

(3) Glover, D. M.; Leibowitz, M. H.; McLean, D. A.; Parry, H. Mutations in aurora prevent centrosome separation leading to the formation of monopolar spindles. Cell 1995, 81, 95-105.

(4) Liu, Q.; Ruderman, J. V. Aurora A, mitotic entry, and spindle bipolarity. Proc. Natl. Acad. Sci. USA 2006, 103, 5811-6.

(5) Lampson, M. A.; Renduchitala, K.; Khodjakov, A.; Kapoor, T. M. Correcting improper chromosome-spindle attachments during cell division. Nat. Cell Biol. 2004, 6, 232-7.

(6) Tanaka, T. U.; Rachidi, N.; Janke, C.; Pereira, G.; Galova, M.; Schiebel, E.; Stark, M. J. R.; Nasmyth, K. Evidence that the Ipl1-Sli15 (Aurora knase-INCENP) complex by altering promotes chromosome bi-orientation kinetochore-spindle pole connections. Cell 2002, 108, 317-329.

(7) Hardwicke, M. A.; Oleykowski, C. A.; Plant, R.; Wang, J.; Liao, Q.; Moss, K.; Newlander, K.; Adams, J. L.; Dhanak, D.; Yang, J. S.; Lai, Z. H.; Sutton, D.; Patrick, D. GSK1070916, a potent Aurora B/C kinase inhibitor with broad antitumor activity in tissue culture cells and human tumor xenograft models. Mol. Cancer Ther. 2009, 8, $1808-1817$.

(8) Yang, J.; Ikezoe, T.; Nishioka, C.; Tasaka, T.; Taniguchi, A.; Kuwayama, Y.; Komatsu, N.; Bandobashi, K.; Togitani, K.; Koeffler, H. P.; Taguchi, H.; Yokoyama, A. AZD1152, a novel and selective aurora B kinase inhibitor, induces growth arrest, apoptosis, and sensitization for tubulin depolymerizing agent or topoisomerase II inhibitor in human acute leukemia cells in vitro and in vivo. Blood 2007, 110, 2034-40.

(9) Xie, F.; Zhu, H. R.; Zhang, H. X.; Lang, Q. Y.; Tang, L. S.; Huang, Q.; Yu, L. In vitro and in vivo characterization of a benzofuran derivative, a potential anticancer agent, as a novel Aurora B kinase inhibitor. Eur. J. Med. Chem. 2015, 89, 310-319.
(10) Fernandez-Miranda, G.; Perez de Castro, I.; Carmena, M.; Aguirre-Portoles, C.; Ruchaud, S.; Fant, X.; Montoya, G.; Earnshaw, W. C.; Malumbres, M. SUMOylation modulates the function of Aurora-B kinase. J. Cell Sci. 2010, 123, 2823-2833.

(11) Girdler, F.; Gascoigne, K. E.; Eyers, P. A.; Hartmuth, S.; Crafter, C.; Foote, K. M.; Keen, N. J.; Taylor, S. S. Validating Aurora B as an anti-cancer drug target. J. Cell Sci. 2006, 119, 3664-3675.

(12) Ruchaud, S.; Carmena, M.; Earnshaw, W. C. Chromosomal passengers: conducting cell division. Nat. Rev. Mol. Cell Biol. 2007, 8, 798-812.

(13) Kimura, M.; Matsuda, Y.; Yoshioka, T.; Okano, Y. Cell cycledependent expression and centrosome localization of a third human Aurora/Ip11-related protein kinase, AIK3. J. Biol. Chem. 1999, 274, $7334-7340$

(14) Li, X. Y.; Sakashita, G.; Matsuzaki, H.; Sugimoto, K.; Kimura, K.; Hanaoka, F.; Taniguchi, H.; Furukawa, K.; Urano, T. Direct association with inner centromere protein (INCENP) activates the novel chromosomal passenger protein, Aurora-C. J. Biol. Chem. 2004, 279, 47201-47211.

(15) Yan, X. M.; Cao, L. H.; Li, Q.; Wu, Y. H.; Zhang, H. X.; Saiyin, H.; Liu, X. H.; Zhang, X. Q.; Shi, Q. H.; Yu, L. Aurora C is directly associated with Survivin and required for cytokinesis. Genes Cells 2005, 10, 617-626.

(16) Bischoff, J. R.; Anderson, L.; Zhu, Y. F.; Mossie, K.; Ng, L.; Souza, B.; Schryver, B.; Flanagan, P.; Clairvoyant, F.; Ginther, C.; Chan, C. S. M. A homologue of Drosophila aurora kinase is oncogenic and amplified in human colorectal cancers. EMBO J. 1998, 17, 30523065.

(17) Katayama, H.; Brinkley, W. R.; Sen, S. The Aurora kinases: role in cell transformation and tumorigenesis. Cancer Metastasis Rev. 2003, $22,451-64$.

(18) Sen, S.; Zhou, H. Y.; White, R. A. A putative serine/threonine kinase encoding gene BTAK on chromosome $20 \mathrm{q} 13$ is amplified and overexpressed in human breast cancer cell lines. Oncogene 1997, 14, 2195-2200.

(19) Lin, Z. Z.; Jeng, Y. M.; Hu, F. C.; Pan, H. W.; Tsao, H. W.; Lai, P. L.; Lee, P. H.; Cheng, A. L.; Hsu, H. C. Significance of Aurora B overexpression in hepatocellular carcinoma. Aurora B Overexpression in HCC. BMC Cancer 2010, 10, 461.

(20) Vischioni, B.; Oudejans, J. J.; Vos, W.; Rodriguez, J. A.; Giaccone, G. Frequent overexpression of aurora B kinase, a novel drug target, in non-small cell lung carcinoma patients. Mol. Cancer Ther. 2006, 5, 2905-2913.

(21) Borisa, A. C.; Bhatt, H. G. A comprehensive review on Aurora kinase: Small molecule inhibitors and clinical trial studies. Eur. J. Med. Chem. 2017, 140, 1-19.

(22) Cicenas, J. The Aurora kinase inhibitors in cancer research and therapy. J. Cancer Res. Clin. Oncol. 2016, 142, 1995-2012.

(23) Glant, T. T.; Besenyei, T.; Kadar, A.; Kurko, J.; Tryniszewska, B.; Gal, J.; Soos, G.; Szekanecz, Z.; Hoffmann, G.; Block, J. A.; Katz, R. S.; Mikecz, K.; Rauch, T. A. Differentially expressed epigenome modifiers, including aurora kinases $\mathrm{A}$ and $\mathrm{B}$, in immune cells in rheumatoid arthritis in humans and mouse models. Arthritis Rheum. 2013, 65, 1725-35.

(24) Ding, L.; Gu, H.; Gao, X.; Xiong, S.; Zheng, B. Aurora kinase a regulates $\mathrm{m} 1$ macrophage polarization and plays a role in experimental autoimmune encephalomyelitis. Inflammation 2015, 38, 800-11.

(25) Ekebergh, A.; Lingblom, C.; Sandin, P.; Wennerås, C.; Mårtensson, J. Exploring a cascade Heck-Suzuki reaction based route to kinase inhibitors using design of experiments. Org. Biomol. Chem. 2015, 13, 3382-3392.

(26) Fan, J.; Nishanian, P.; Breen, E. C.; McDonald, M.; Fahey, J. L. Cytokine gene expression in normal human lymphocytes in response to stimulation. Clin. Diagn. Lab. Immunol. 1998, 5, 335-40.

(27) Olsen, I.; Sollid, L. M. Pitfalls in determining the cytokine profile of human T cells. J. Immunol. Methods 2013, 390, 106-12.

(28) Sousa, I. G.; Simi, K. C. R.; do Almo, M. M.; Bezerra, M. A. G.; Doose, G.; Raiol, T.; Stadler, P. F.; Hoffmann, S.; Maranhao, A. Q.; Brigido, M. M. Gene expression profile of human T cells following a 
single stimulation of peripheral blood mononuclear cells with antiCD3 antibodies. BMC Genomics 2019, 20, 593.

(29) Adams, N. D.; Adams, J. L.; Burgess, J. L.; Chaudhari, A. M.; Copeland, R. A.; Donatelli, C. A.; Drewry, D. H.; Fisher, K. E.; Hamajima, T.; Hardwicke, M. A.; Huffman, W. F.; Koretke-Brown, K. K.; Lai, Z. V.; McDonald, O. B.; Nakamura, H.; Newlander, K. A.; Oleykowski, C. A.; Parrish, C. A.; Patrick, D. R.; Plant, R.; Sarpong, M. A.; Sasaki, K.; Schmidt, S. J.; Silva, D. J.; Sutton, D.; Tang, J.; Thompson, C. S.; Tummino, P. J.; Wang, J. C.; Xiang, H.; Yang, J.; Dhanak, D. Discovery of GSK1070916, a potent and selective inhibitor of Aurora B/C kinase. J. Med. Chem. 2010, 53, 3973-4001.

(30) Kobayashi, A.; Kajiyama, S. I.; Inawaka, K.; Kanzaki, H.; Kawazu, K. Nostodione-a, a Novel Mitotic Spindle Poison from a Blue-Green-Alga Nostoc-Commune. Z. Naturforsch., C: J. Biosci. 1994, 49, 464-470.

(31) Abe, Y.; Okumura, E.; Hosoya, T.; Hirota, T.; Kishimoto, T. A single starfish Aurora kinase performs the combined functions of Aurora-A and Aurora-B in human cells. J. Cell Sci. 2010, 123, 39783988.

(32) Fernandez-Guerra, A.; Aze, A.; Morales, J.; Mulner-Lorillon, O.; Cosson, B.; Cormier, P.; Bradham, C.; Adams, N.; Robertson, A. J.; Marzluff, W. F.; Coffman, J. A.; Geneviere, A. M. The genomic repertoire for cell cycle control and DNA metabolism in S-purpuratus. Dev. Biol. 2006, 300, 238-251.

(33) Bain, J.; Plater, L.; Elliott, M.; Shpiro, N.; Hastie, C. J.; Mclauchlan, H.; Klevernic, I.; Arthur, J. S. C.; Alessi, D. R.; Cohen, P. The selectivity of protein kinase inhibitors: a further update. Biochem. J. 2007, 408, 297-315.

(34) Hastie, C. J.; McLauchlan, H. J.; Cohen, P. Assay of protein kinases using radiolabeled ATP: a protocol. Nat. Protoc. 2006, 1, 968-971.

(35) Elkins, J. M.; Santaguida, S.; Musacchio, A.; Knapp, S. Crystal structure of human aurora B in complex with INCENP and VX-680. J. Med. Chem. 2012, 55, 7841-8.

(36) Sessa, F.; Villa, F. Structure of Aurora B-INCENP in complex with barasertib reveals a potential transinhibitory mechanism. Acta Crystallogr., Sect. F: Struct. Biol. Commun. 2014, 70, 294-8.

(37) Pettersen, E. F.; Goddard, T. D.; Huang, C. C.; Couch, G. S.; Greenblatt, D. M.; Meng, E. C.; Ferrin, T. E. UCSF Chimera-a visualization system for exploratory research and analysis. J. Comput. Chem. 2004, 25, 1605-12.

(38) Morris, G. M.; Huey, R.; Lindstrom, W.; Sanner, M. F.; Belew, R. K.; Goodsell, D. S.; Olson, A. J. AutoDock4 and AutoDockTools4: Automated docking with selective receptor flexibility. J. Comput. Chem. 2009, 30, 2785-91.

(39) Hanwell, M. D.; Curtis, D. E.; Lonie, D. C.; Vandermeersch, T.; Zurek, E.; Hutchison, G. R. Avogadro: an advanced semantic chemical editor, visualization, and analysis platform. J. Cheminf. 2012, 4, 17.

(40) Trott, O.; Olson, A. J. AutoDock Vina: improving the speed and accuracy of docking with a new scoring function, efficient optimization, and multithreading. J. Comput. Chem. 2010, 31, 45561. 